\title{
Mauricio Pezo
}

El trabajo de Pezo nos recuerda la existencia de otras urbanidades (no sólo la santiaguina) en Chile. La ciudad de Concepción, sus lluvias y cielo amplio, sirve como soporte y escenario de estas reflexiones materializadas: a veces más cerca del campo del arte, otras más cerca de la arquitectura, bacen de la monotonía y una supuesta indiferencia la berramienta de intervención en un contexto calmo habitado por estudiantes universitarios y parte importante de la clase media profesional chilena.

Pezo's work reminds us that other forms of city-building exist in Chile, not just Santiago's. Concepción, with its rain and wide skies, is base and stage for these materialized reflections. At times closer to art, at others, to architecture, they make monotony and an apparent indifference the tools of intervention in a tranquil context, inhabited by university students and a significant section of Chile's professional middle-class.

\section{Arte estéril}

Cualquier cosa puede acaecer o no acaecer y todo el resto permanece igual. L. Wittgenstein.

$1100.000 \mathrm{cc}(21.06 .01)$ 100 bolsas transparentes, 100 litros de agua, colgando bajo 25 marquesinas de la calle Barros Arana, Concepción, e el primer día del invierno

2 Levantamiento tapas de alcantarillado, centro de concepción.

3 y 4 Color Circular (05.03.01) 12 colores de látex, aplicados sobre 520 tapas de

alcantarillado en las 49 cuadras centrales de Concepción. Tres instrucciones de ejecución: nunca chorrear ni fuera del círci manchar el marco metálico de las tapas, y nunca pintar del mismo color dos tapas cercans.

5 Brújula del Sur (02.11.00) 100 globos blancos (inflados con helio), 300 metros de lienza de algodón, 100 piedras redondas, sobre una línea el centro fundacional de el centro fundacional de ciudad, Plaza
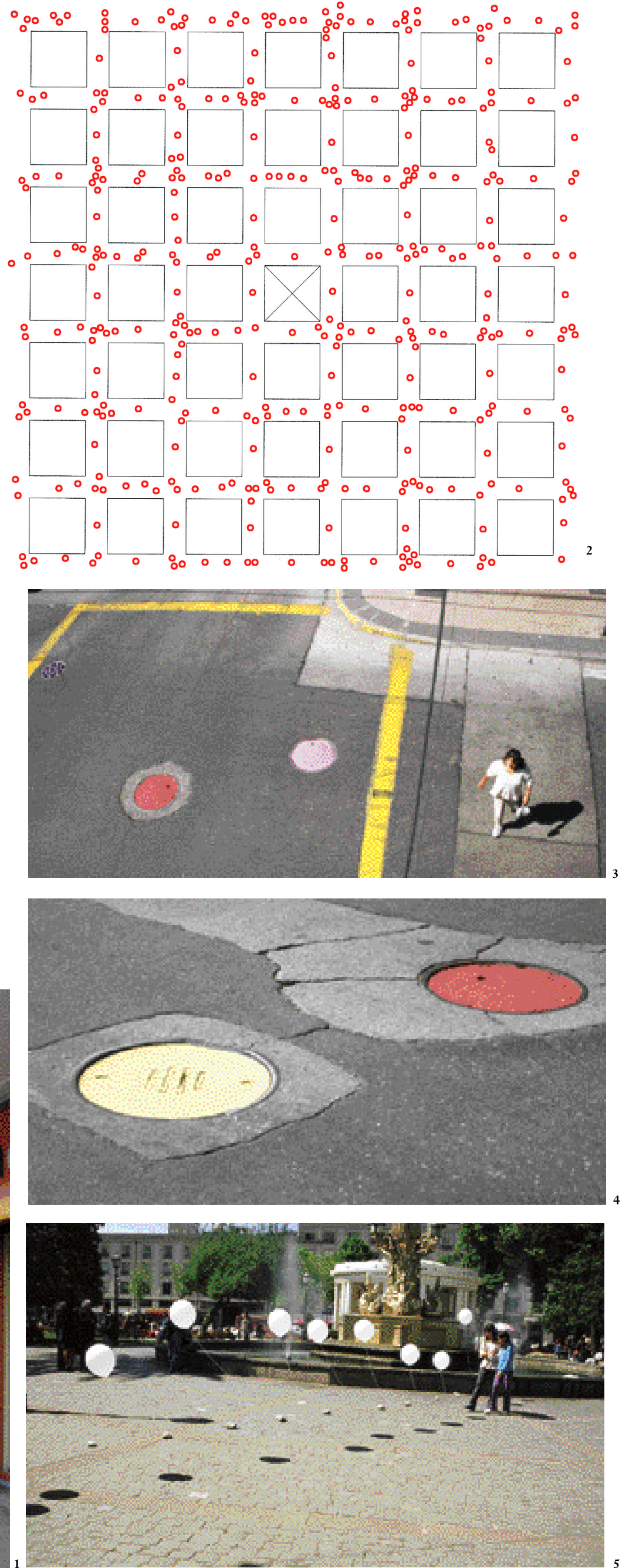

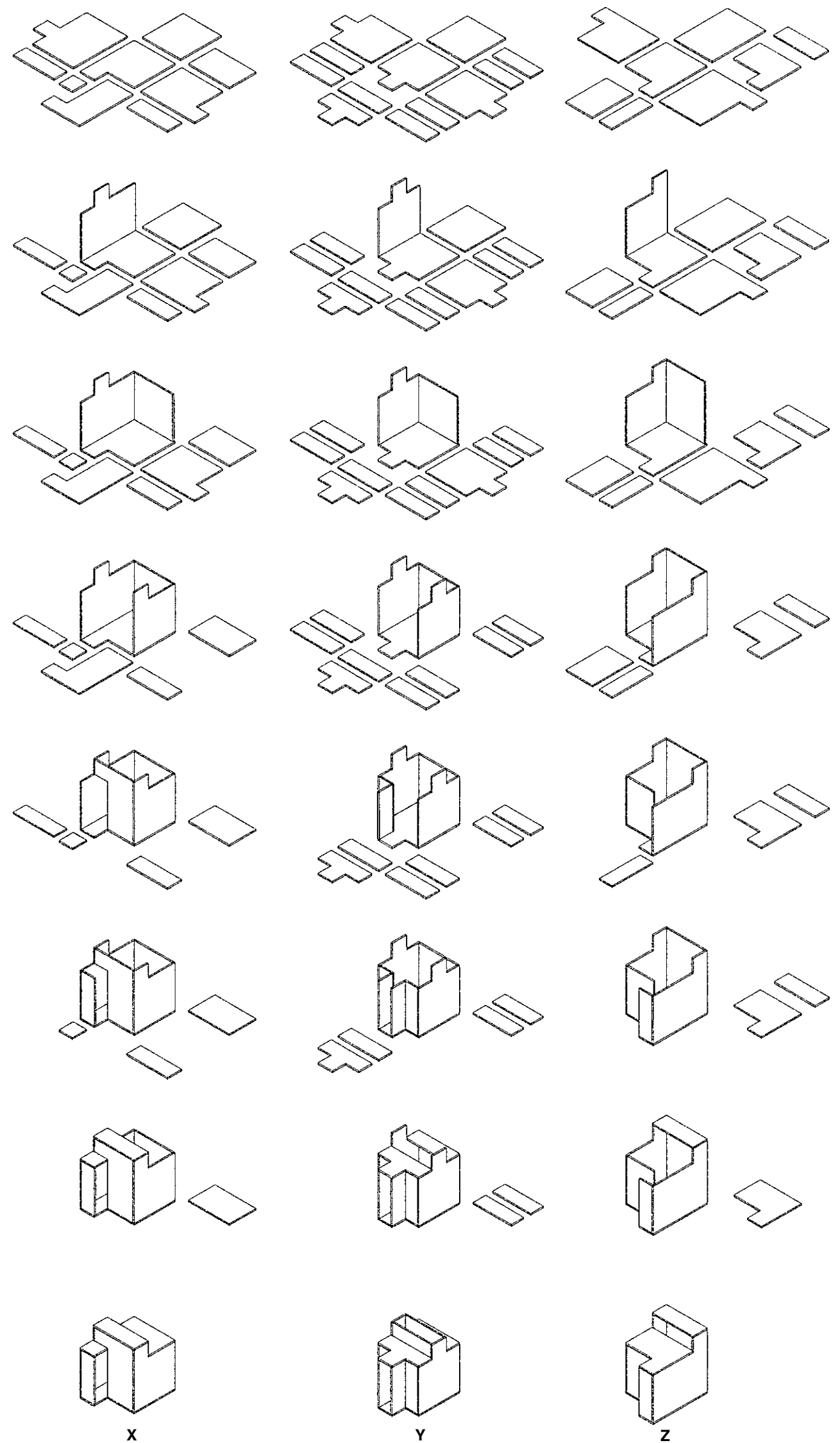

$\mathbf{X}, \mathbf{Y}, \mathbf{Z}$, módulos UBB Secuencia de montaje de módulos de exposición

Describir lo que estas obras son es todo lo contrario de hacer un despliegue de su composición; de cuáles son sus elementos, sus relaciones o su posición. Una descripción sería una representación de lo que no son; confundiría las acciones con el cuerpo que estas obras no tienen. Estas imágenes no son más que registros de obras que ya no existen; registros que sólo pretenden perdurar como un catastro de sus ideas.

$(0+0=0)^{1}$

La obra estéril aparece como una construcción intelectual que desaparece en el momento en que la obra se construye y que (eventualmente) reaparece sin explicación cuando la obra se va borrando. La obra estéril propone una lectura de eventos. Despliega una serie de puntos o de instantes de extrañamiento. Actúa sobre la ciudad tomándola como pretexto para proponer una nueva relación entre el lugar y el habitante cotidiano. Lo extraño propone intensificar levemente sus relaciones. A diferencia de la contemplación de un cuerpo escultórico, el público urbano (personaje en movimiento y ocupado) recorre la obra. Estas acciones de arte son percibidas como la experiencia de un acontecimiento físico, distraído y casual. La obra simplemente actúa. Se entiende por su presencia como un objeto de pura seducción (o puro desajuste). Su lectura es siempre parcial; de fragmentos reiterados. La totalidad de la obra es simulada como una construcción mental (una tapa de color es sólo una tapa pintada hasta que se descubre una nueva tapa de un color diferente que simultáneamente se funde con el color anterior). Su disposición es aleatoria. Es dispersa, desconectada; es un compuesto de lugares menores y separados. De puntos debilitados por su distancia. No tiene jerarquías. Cada instante es un lugar insignificante que evita el protagonismo; que se insinúa; que no se expone. Son lugares que se mantienen en el anonimato. Sin autor; sin rostro ni firma. Que, a diferencia del grafitti, no son actos de resistencia que transgreden su contexto. En suma, una obra estéril propone algo así como una lectura no enfática; la leve posibilidad de informar sobre algo; de ser una información que ni siquiera pretenda comunicar algo más que su propia indiferencia.

\section{$(\mathbf{n}+\mathbf{0}=\mathbf{n})^{2}$}

Nada que sea por nada que sea es una frase que presenta lo que es por lo que no es. Nada que sea, la primera parte, es algo; por nada que sea, la segunda parte, se refiere a todo lo que no es. Algo así como un nombre y su adjetivo. El nombre de algo y un adjetivo que retorna al nombre. Tautología, retórica; lo que sea. Descubrir que una frase no tiene sentido ocurre más allá de la frase. De hecho, lo único que garantiza la frase es la experiencia de leerla, independiente de su comprensión o de su importancia. Al parecer el hermetismo conceptual, el exceso intelectual de la obra, supera la sensibilidad del espectador. La saturación convierte la obra en un espectáculo anestésico; en un artefacto de la insensibilidad. La obra pasa a ser el medio de un efecto sedante que provoca una mirada tangente, desencantada y sin detención. Cuando este silencioso efecto se encarna en el principio de la obra, la obra soporta la indiferencia y el agotamiento del espectador. Una obra así no exige atención ni sensibilidad. No es más que un placebo; una dosis de nada, que actúa por presencia inmediata, como un accidente o una casualidad. Todo lo contrario de un acto político; todo lo contrario de una imitación de la naturaleza o de una crítica a la cultura. Una obra estéril está vacía, llena de ausencia, con elementos sin capacidades, desnaturalizados en su propia impotencia y sin otra cualidad que la de su mínima existencia ${ }^{3}$. Aun así, potencial. La obra estéril, entonces, sólo pretende registrar momentos insignificantes. Su presencia busca abrir un campo de sugerencias.. Actúa como proposición, como situación inestable y de lectura variable; como repetición de un signo vacío que exalta su propia monotonía. 
$\mathbf{X}, \mathbf{Y}, \mathbf{Z}$, módulos UBB

(10.12.01):

27 paneles de madera, 6 paneles

de aluminio y acrílico, instalación

inicial en el Parque Ecuador de

Concepción.
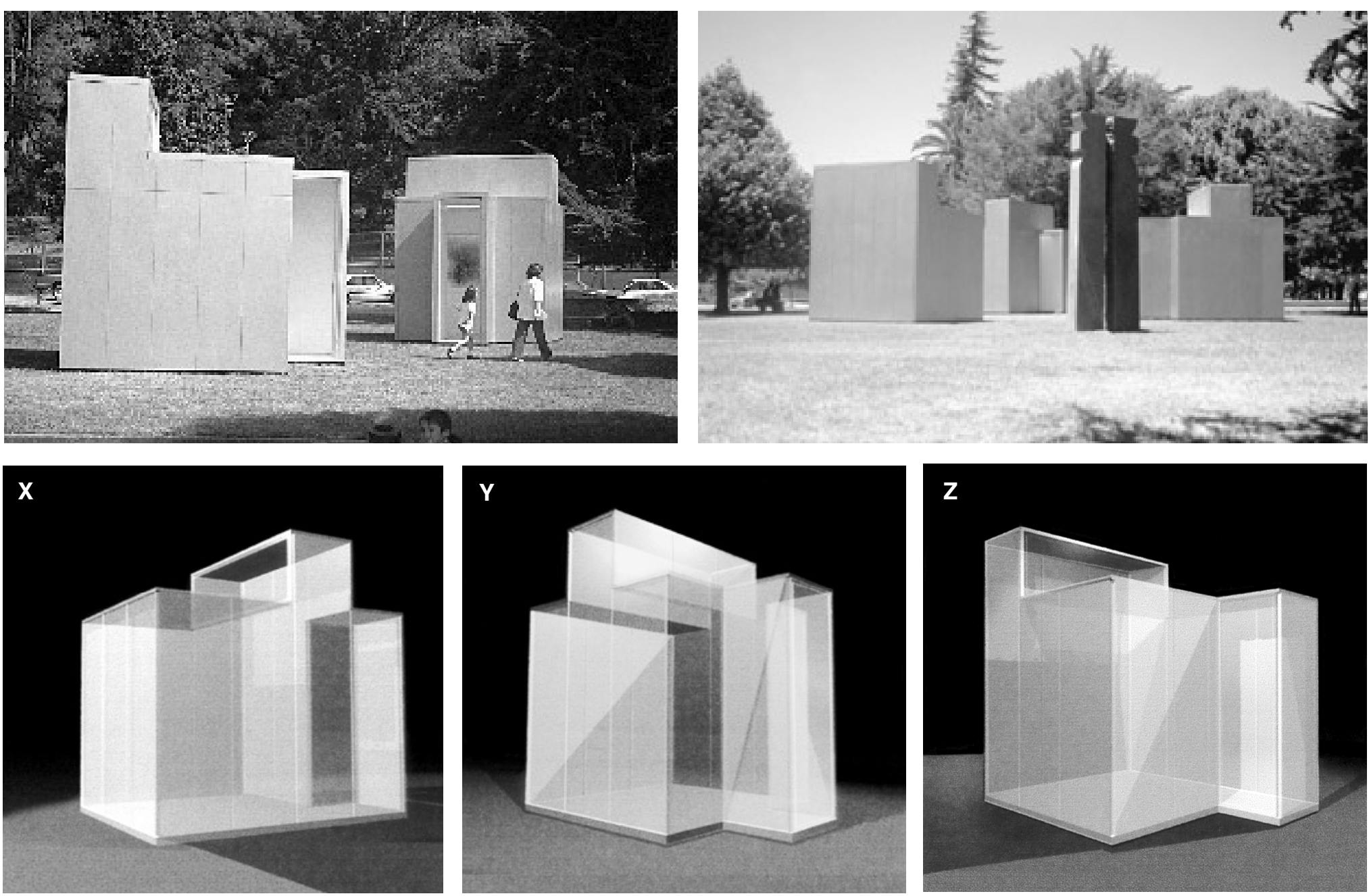

$(\mathbf{x}+\mathrm{y}+\mathrm{z}=\mathbf{0})^{4}$

Se ha propuesto una obra autónoma; sin posición, sin orientación y para cualquier lugar. Una vez hecho, se admite que cada planta sea un estricto abatimiento de su corte. Que sean tres salas; tres espacios cúbicos independientes, aislados y herméticos. Que sirvan de soporte esencial para instalaciones de arte. Que a la función expositiva (su espacio neutral) se le sumen dos funciones necesarias (vitales); un acceso y la iluminación natural. Que estas otras funciones se traduzcan en dos volúmenes de luz; uno vertical y otro horizontal y suspendido. Que con estas variaciones se identifique cada silueta. Que las tres salas aparezcan como tres objetos (escultóricos); sin referencias de escala y con una disposición aleatoria y dispersa. Que se vean como cuerpos sólidos, volúmenes pesados y macizos. Que esto sea pura apariencia invertida. Que en verdad sea una composición de paneles ensamblados. Que no tengan uniones fijas. Que puedan ser desmontados para su traslado. Que no sea más que una arquitectura construida para desaparecer junto con el espectáculo que contiene.
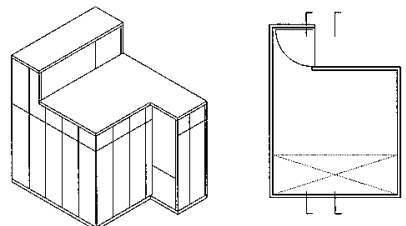

p1
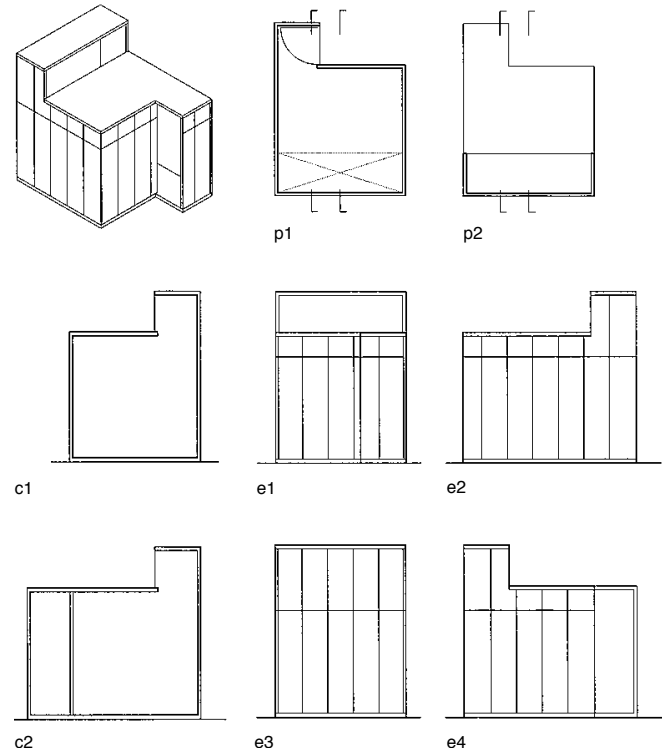

Plantas, cortes y elevaciones de módulo z

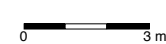

